\title{
Variations in MAP kinase gladiators and risk of differentiated thyroid carcinoma
}

\author{
FAIZA A. RASHID ${ }^{1}$, GHULAM HASSAN BHAT ${ }^{2 *}$, MOSIN S. KHAN $^{2 *}$, \\ SOBIA TABASSUM $^{1}$ and MOHAMMAD HAYAT BHAT ${ }^{3}$ \\ ${ }^{1}$ Department of Biological Sciences, International Islamic University, Islamabad 1243, Pakistan; \\ Departments of ${ }^{2}$ Biochemistry and ${ }^{3}$ Endocrinology, Government Medical College and \\ Associated Shri Maharaja Hari Singh and Super Speciality Hospital, Srinagar, Jammu and Kashmir 190010, India
}

Received March 27, 2021; Accepted October 27, 2021

DOI: $10.3892 / \mathrm{mco} .2021 .2478$

\begin{abstract}
Thyroid carcinoma (TC) accounts for $\sim 2.1 \%$ of newly diagnosed cancer cases. Mutations in KRAS, HRAS, $N R A S$ and $B R A F$ are primary participants in the development and progression of various types of malignancy, including differentiated TC (DTC). Therefore, the present prospective cohort study aimed to screen patients with DTC for variations in $R A S$ gene family and $B R A F$ gene. Exon 1 and 2 of $K R A S$, $H R A S, N R A S$ and exon 15 of BRAF gene were screened for hotspot mutations in 72 thyroid tumor and adjacent normal tissue samples using di-deoxy Sanger sequencing. HRAS T81C mutation was found in $21 \%$ (15 of 72) of DTC tissue samples, therefore this mutation was investigated in blood samples from patients with DTC and controls as a genetic polymorphism. In addition, HRAS T81C genotypes were determined in 180 patients with DTC and 220 healthy controls by performing restriction fragment length polymorphism. $B R A F^{\mathrm{V} 600 \mathrm{E}}$ mutation was confined to classical variant of papillary thyoid cancer (CPTC; 44.4\%) and was significantly associated with multifocality and lymph node (LN) metastasis. No mutation was found in exons 1 and 2 of KRAS and NRAS and exon 2 of HRAS genes, however, mutation was detected in exon 1 of HRAS gene (codon 27) at nucleotide position 81 in $21 \%$ (15 of 72) of DTC tumor tissue samples. Furthermore, HRAS T81C single nucleotide polymorphism was significantly associated with the risk of DTC with variant genotypes more frequently detected in cases compared with controls $(\mathrm{P} \leq 0.05)$. Moreover, frequency of variant genotypes $(\mathrm{TC}+\mathrm{CC})$ was
\end{abstract}

Correspondence to: Dr Mosin Saleem Khan, Department of Biochemistry, Government Medical College and Associated Shri Maharaja Hari Singh and Super Speciality Hospital, 10 Karan Nagar, Srinagar, Jammu and Kashmir 190010, India

E-mail: mosinsaleemkhan@gmail.com

\section{*Contributed equally}

Key words: thyroid cancer, differentiated thyroid cancer, KRAS, $H R A S, N R A S$, single nucleotide polymorphism significantly higher among DTC cases with no history of smoking, males, greater age, multifocality and LN metatasis compared with healthy controls $(\mathrm{P}<0.05) . B R A F^{\mathrm{V} 600 \mathrm{E}}$ mutation was primarily present in CPTC and associated with an aggressive tumor phenotype but mutations in $R A S$ gene family were not present in patients with DTC. HRAS T81C polymorphism may be involved in the etiopathogenesis of DTC in a Pakistani cohort. Furthermore, testing for the $B R A F^{\mathrm{V} 600 \mathrm{E}}$ mutation may be useful for selecting initial therapy and follow-up monitoring.

\section{Introduction}

Thyroid cancer (TC) has become a global concern due to its increasing incidence rate and was ranked 9th among all cancers in 2020, with $\sim 586,000$ cases globally and 3 times higher incidence in women compared with men (1). Due to more stringent diagnostic practices, TC incidence has begun to decline in women $(2,3)$. TC generally derives from epithelial follicular cells, also known as C cells, and $\sim 90 \%$ of TC cases are well-differentiated (WD). DTC is further classified as papillary (PTC) or follicular (FTC), depending on histopathological criteria (4). DTCs frequently have genetic alterations in the gladiators, molecules associated with the mitogen activated protein kinase (MAPK) signaling pathway, including $R E T / P T C$ rearrangement and point mutations in $R A S$ and $B R A F$ genes, leading to activation of the MAPK pathway (5).

BRAF serine-threonine kinase belongs to the family of RAF proteins. $B R A F$ mutations are oncogenic driver mutations associated with solid tumors, including thyroid carcinoma. Among all $B R A F$ mutations identified, $B R A F^{\mathrm{V} 600 \mathrm{E}}$ accounts for $>90 \%$ (5). Missense mutation results in $\mathrm{T}>\mathrm{A}$ transversion at nucleotide position 1799 (c.T1799A), leading to substitution of valine (V) into glutamic acid (E) at codon 600, which disrupts interactions between the activation loop and ATP binding site and allows formation of new interactions that keep the protein in a catalytically active conformation, resulting in continuous phosphorylation of MEK $(6,7)$. The prevalence of $B R A F^{\mathrm{V} 600 \mathrm{E}}$ in $\mathrm{TC}$ is more heterogenous in Asian populations, spanning 28.2-90.0\% (8). BRAF mutations are highly prevalent in papillary carcinoma with classical histology and in the tall cell variant, but are rare in the follicular variant (9). In many studies, the presence of $B R A F$ mutation has been associated 
with aggressive tumor characteristics, such as extrathyroidal extension, advanced tumor stage at presentation, tumor recurrence and lymph node $(\mathrm{LN})$ or distant metastasis $(9,10)$. Mutations in $R A S$ and $B R A F$ genes rarely overlap in the same tumor and are mutually exclusive $(5,11)$.

Mammalian cells contain three functional potooncogenes of the RAS family known as KRAS (Kristan), HRAS (Harvey) and NRAS (Neuroblastoma) (12). These genes encode small GTPases, which are primary participants in the transmission of growth signals from cell membrane receptors to the nucleus (13). Gain of function mutations in the $R A S$ gene family result in continuous stimulation of cell growth and proliferation, even in the absence of extracellular signals (14), resulting in tumorigenesis. Point mutations in the $R A S$ gene (exon 1; codons 12 and 13) increase its affinity for GTP or inactivate its autocatalytic GTPase function (exon 2; codon 61) (15) thereby, permanently activating the MAPK and P13K-AKT pathways. Point mutations of $R A S$ occur variably in all types of thyroid follicular cell-derived tumors. In FTC, $R A S$ mutations are found in $40-50 \%$ of tumors (16) and may also correlate with tumor dedifferentiation and less favorable prognosis (17). In PTC, RAS mutations are relatively infrequent and occur in $\sim 10 \%$ of tumors (18). Papillary carcinoma with $R A S$ mutations almost always exhibit follicular variant histology; this mutation also correlates with significantly less prominent nuclear features of papillary carcinoma, more frequent encapsulation and lower rate of LN metastasis (19). Studies have reported an association between RAS mutations and more aggressive behavior of PTC and higher frequency of distant metastasis $(20,21)$.

Besides the mutation hotspots of KRAS, HRAS and NRAS, inherited single nucleotide polymorphism (SNP) in exon 1 of HRAS T81C ( $r s 12628)$ is associated with risk of different types of human cancer. HRAS T81C homozygous variant genotype (CC) has been associated with bladder cancer, chronic myeloid leukemia and TC $(22,23)$. This SNP, located at codon 27 of exon 1, does not disturb the p21 protein structure and function as codons CAC and CAT both encode histidine (His27His). This variation instead disturbs expression of $H R A S$ by inducing overexpression (24) and may be associated with additional polymorphic loci inside regulatory sections of HRAS. Earlier studies also investigated the role of HRAS T81C SNP in TC and associated it with aneuploidy in follicular tumors of thyroid $(22,24)$.

The present study hypothesized that mutations in hotspot regions of RAS (KRAS, HRAS, NRAS); BRAF and presence of $H R A S T 81 C$ variation may modulate susceptibility to TC. To verify this hypothesis, these mutations and polymorphisms in TC were assessed to ascertian their association and functional role in thyroid carcinogenesis of Pakistani population.

\section{Materials and methods}

Study design. The present investigation was a prospective cohort study conducted by the Department of Biological Sciences, International Islamic University, Islamabad; Department of Biochemistry, Pakistan Institute of Medical Sciences (PIMS) Islamabad and Combined Military Hospital $(\mathrm{CMH})$ Muzaffarabad, Pakistan. Ethical approval was obtained from Ethical Review Board of PIMS. All participants enrolled in the study provided written informed consent allowing the use of their tissue and blood samples. Patients with any genetic disorder, other type of cancer or receiving chemotherapy were excluded from the study.

Study subjects and sample collection for analysis of BRAF and RAS mutations. Thyroid tumor and adjacent normal tissue $(\mathrm{n}=72$; distance, $5-10 \mathrm{~mm}$ ) samples were obtained from histologically confirmed patients with DTC who underwent total or hemi-thyroidectomy in the Department of General Surgery, PIMS and CMH, Pakistan between 2016 and 2018. Tissue samples were collected in sterile vials and immediately stored at $-80^{\circ} \mathrm{C}$ until further processing.

Study subjects and sample collection for HRAS T81C genotyping. A total of 180 peripheral blood samples from patients with DTC were collected from Department of General Surgery, PIMS and CMH, Pakistan, between 2017 and 2019. In addition, 220 blood samples were collected from ethnicity-matched healthy controls free from any type of malignancy, who visited hospitals for routine checkup. A total of $\sim 3 \mathrm{ml}$ each blood was collected in EDTA-coated vials from patients with DTC and healthy controls and stored at $-80^{\circ} \mathrm{C}$ until further processing.

DNA extraction. DNA from fresh tumor and adjacent normal tissue was isolated using PureLink Genomic DNA Mini kit (Invitrogen; Thermo Fisher Scientific, Inc.). A total of 5 formalin-fixed, paraffin embedded (FFPE) tissue samples were retrieved from Department Pathology, PIMS and CMH, Pakistan, which had not been immediately collected following resection of thyroid gland. DNA was isolated from FFPE tissue using QIAamp DNA FFPE Tissue kit (Qiagen GmbH). Furthermore, DNA was isolated from blood samples of cases and controls using QIAamp DNA Blood Mini kit (Qiagen $\mathrm{GmbH})$. Quantification of isolated DNA was performed using NanoDrop Microvolume Spectrophotometer (Thermo Fisher Scientific, Inc.).

$P C R$. The primer sequences used to amplify exon 15 of $B R A F$; exon 1 and 2 of each KRAS, HRAS and NRAS gene along with their annealing temperatures and amplicon size are given in Table I. Each PCR reaction was executed in a final volume of $50 \mu 1$ containing 2 each forward and reverse primers $(20 \mathrm{pM} / \mu \mathrm{l}), 3$ genomic DNA, 18 sterile water and $25 \mu \mathrm{l}$ GoTaq 2X Green Master mix (Promega Corporation). PCR reaction was performed using the following thermocycling conditions: Initial denaturation for $5 \mathrm{~min}$ at $95^{\circ} \mathrm{C}$, followed by denaturation of template DNA for $35 \mathrm{sec}$ at $94^{\circ} \mathrm{C}$, annealing for $35 \mathrm{sec}$ and primer extension for $35 \mathrm{sec}$ at $72^{\circ} \mathrm{C}$. Denaturation, annealing and primer extension steps were repeated for 35 cycles. Final extension was performed for $5 \mathrm{~min}$ at $72^{\circ} \mathrm{C}$ as previously described $(22,25)$. The PCR product was run on $2 \%$ agarose gel and analysed using AlphaImager ${ }^{\mathrm{TM}}$ Gel Imaging System (ProteinSimple). Double distilled water $\left(\mathrm{ddH}_{2} \mathrm{O}\right)$ was used as a negative control.

Di-deoxy Sanger sequencing. Gene JET PCR Purification kit (Thermo Fisher Scientific, Inc.; cat. no. K0702) was used to purify PCR products according to the manufacturer's instructions. The purified PCR products of different DNA samples 
Table I. Primer sequences, annealing temperature and product size of exons for PCR amplification.

\begin{tabular}{|c|c|c|c|c|}
\hline Gene & Exon & Primer Sequence, $5^{\prime} \rightarrow 3^{\prime}$ & Annealing temperature, ${ }^{\circ} \mathrm{C}$ & Product size, bp \\
\hline \multirow[t]{2}{*}{$B R A F$} & 15 & F: TCATAATGCTTGCTCTGATAGGA & & \\
\hline & & R: GGCCAAAAATTTAATCAGTGGA & 58 & 224 \\
\hline \multirow[t]{2}{*}{$N R A S$} & 1 & F: AGTACTGTAGATGTGGCTCGCC & & \\
\hline & & R: CCTCACCTCTATGGTGGGATC & 60 & 185 \\
\hline \multirow[t]{2}{*}{$N R A S$} & 2 & F: CCССТTACССТCCACAC & & \\
\hline & & R: AGGTTAATATCCGCAAATGAC & 55 & 196 \\
\hline \multirow[t]{2}{*}{$H R A S$} & 1 & F: CAGGAGACCCTGTAGGAGGA & & \\
\hline & & R: GGCACCTGGACGGCGGCGCTAG & 60 & 186 \\
\hline \multirow[t]{2}{*}{$H R A S$} & 2 & F: TCCTGCAGGATTCCTACCGG & & \\
\hline & & R: GGTTCACCTGTACTGGTGGA & 55 & 194 \\
\hline \multirow[t]{2}{*}{$K R A S$} & 1 & F: GTACTGGTGGAGTATTTGAT & & \\
\hline & & R: TGAAAATGGTCAGAGAAACC & 55 & 285 \\
\hline \multirow[t]{2}{*}{$K R A S$} & 2 & F: CCTTCTCAGGATTCCTACAG & & \\
\hline & & R: TTATTTATGGCAAATACACAAATA & 55 & 1585 \\
\hline
\end{tabular}

F, forward; R, reverse.

were subjected to Sanger sequencing using SeqStudio Genetic Analyzer (Applied Biosystems; Thermo Fisher Scientific, Inc.).

PCR-restriction fragment length polymorphism (RFLP). For HRAS T81C genotyping, exon 1 of HRAS was amplified by PCR as previously described $(15,22)$, yielding a $186 \mathrm{bp}$ product (Table I). For RFLP, PCR product was subjected to digestion with DraIII (Thermo Fisher Scientific, Inc.) restriction enzyme at $37^{\circ} \mathrm{C}$ for $16 \mathrm{~h}$. The homozygous variant genotype (CC) was cut into fragments of 128 and $58 \mathrm{bp}$; homozygote wild genotype (TT) yielded a single fragment of $186 \mathrm{bp}$ while heterozygous variant (TC) yielded 186, 128 and 58 bp fragments. Digestion products were subjected to $3 \%$ agarose gel electrophoresis and documented using AlphaImager ${ }^{\mathrm{TM}}$ Gel Imaging System (ProteinSimple).

Statistical analysis. Data are presented as the mean \pm SD of three independent repeats. $\chi^{2}$ test was used to compare cases and controls in terms of categorical variables, such as age, sex, histological type, thyroid stimulating hormone (TSH) levels, residence and smoking status using multiple logistic regression analysis. A goodness of fit test was applied to assess whether polymorphisms between cases and controls were present in Hardy-Weinberg equilibrium. Estimation of the relative risk and degree of association between genotytpes and risk factors of $\mathrm{TC}$ were determined by calculation of the odds ratio (OR) with $95 \%$ confidence interval (CI). $\mathrm{P} \leq 0.05$ was considered to indicate a statistically significant difference. All statistical analysis was performed using SPSS V. 23.0. software (IBM Corp.).

\section{Results}

Characteristics of patients with TC for tissue analysis. For mutation analysis of BRAF, HRAS, KRAS and NRAS genes, a total of 72 DTC and adjacent normal tissue samples were taken. Table II shows the frequency distribution of selected socio-demographic and clinicopathological characteristics of DTC cases for mutational analysis. Among DTC cases, $30.6 \%$ (22 of 72) were male and $69.4 \%$ (50 of 72) were female. A total of 54 of $72(75 \%)$ patients were $<55$ years of age and 18 of $72(25 \%)$ were $\geq 55$ years of age. The number of non-smokers and smokers were $65(90 \%)$ and $7(10 \%)$ respectively. Furthermore, TSH levels were normal and elevated in $58.4 \%$ (42 of 72) and $41.6 \%$ (30 of 72) of cases, respectively. The normal reference range for TSH was taken as $0.35-6.0 \mu \mathrm{IU} / \mathrm{ml}$. History of benign thyroid disease (BTD; including thyroid adenoma, goitre and thyrotoxicosis) was found in $80 \%$ of patients. WDTC was present in $94.0 \%$ (68 of 72) of patients. Vascular/capsular invasion and lymph node metastasis was positive in 43.1 and $55.8 \%$ of patients, respectively. Other clinicopathological details of TC cases are shown in Table II.

Mutational analysis of BRAF and RAS genes. Exon 15 of $B R A F$ gene was screened for presence of hotspot mutations in DTC tumor and adjacent normal tissue. T to A transversion was noted at nucleotide position 1,799 (c.T1799A) in $28 \%$ (20 of 72) of patients with DTC, resulting in substitution of $\mathrm{V}$ into $\mathrm{E}$ at codon 600. BRAF mutation was not found in adjacent normal tissue samples. Partial electropherograms showing $\mathrm{T}$ to $\mathrm{A}$ tranversion in $B R A F^{\mathrm{V} 600 \mathrm{E}}$ mutation are depicted in Fig. 1. $B R A F^{\mathrm{V} 600 \mathrm{E}}$ mutation was not found in any patients with follicular variant of PTC (FPTC). $B R A F^{\mathrm{V} 600 \mathrm{E}}$ mutation was confined to classical variant of PTC (CPTC) $(\mathrm{P}=0.0001)$. A higher frequency of $B R A F^{\mathrm{V} 600 \mathrm{E}}$ mutation $(41 \%)$ was significantly associated with higher tumour focality and LN metastasis $(\mathrm{P}=0.03$ and 0.005 ; Table III). Table III shows the association between $B R A F^{\mathrm{V} 600 \mathrm{E}}$ mutation status with demographic and clinicopathological features of patients with DTC. 
A CTACAGT GAAATC

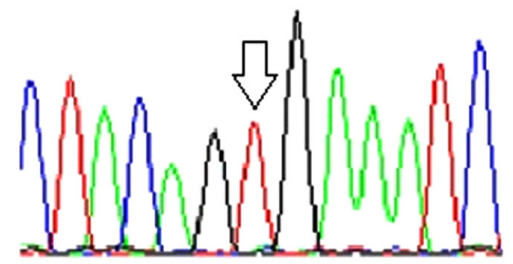

B CTACAGTGAAATC

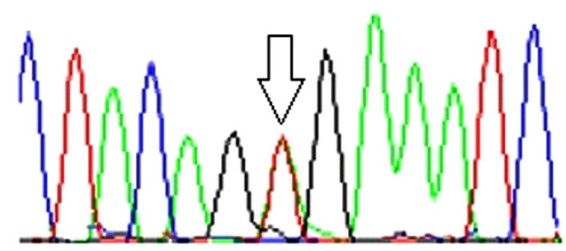

Figure 1. Partial electropherograms of exon 15 of the $B R A F$ gene. (A) Wild sequence with no mutation. (B) Mutation (transversion) at nucleotide position 1799 (c.T1799A).
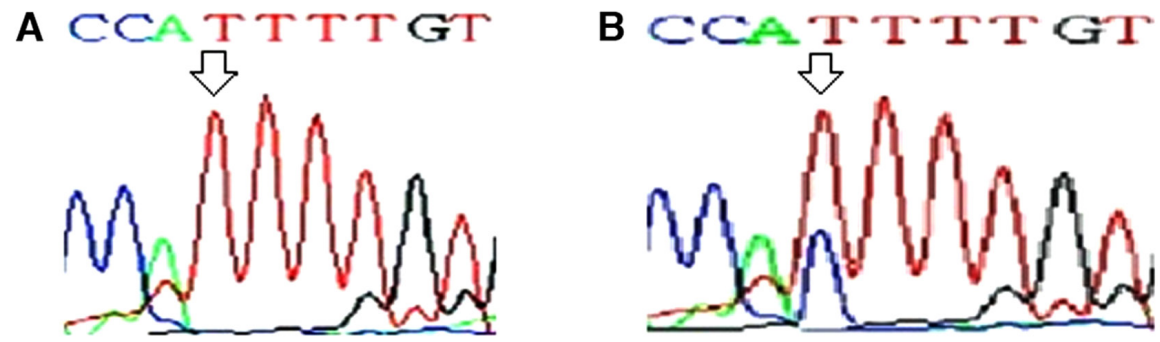

Figure 2. Partial electropherograms of HRAS exon 1. (A) Wild sequence with no mutation. (B) Mutation at nucleotide position 81 (c.T81C).
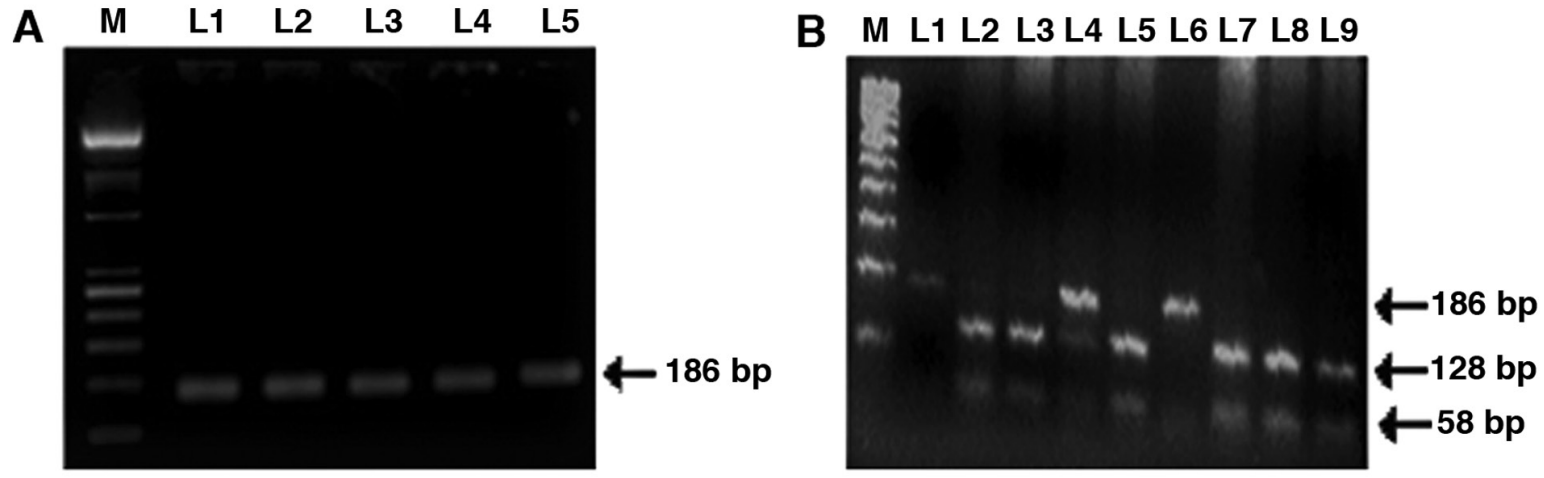

Figure 3. Genotyping of HRAS T81C single nucleotide polymorphism. (A) PCR amplified product of HRAS exon 1 (186 bp) (B) Fragment digestion of PCR product by DraIII restriction enzyme. Wild genotype (TT; $186 \mathrm{bp}$ ) is shown in lanes 1 and 6 ; heterozygous genotype (TC; 186,128 and 58 bp) is shown in lane 4; homozygous variant (CC; 128 and 58 bp) is shown in lanes 2, 3, 5 and 7-9; M, 100 bp ladder.

Exons 1 and 2 of KRAS, NRAS and HRAS genes were screened for presence of hotspot mutations in codons 12,13 and 61 of a RAS gene family. No mutation was found in any of these codons in DTC tumor or adjacent normal tissue samples. Following DNA sequencing of $H R A S$, a frequent substitution of $\mathrm{T}$ to $\mathrm{C}$ was found in exon 1 at codon 27 (cDNA position 81), which was present in wobble base position (Fig. 2). HRAS T81C mutation was found in $21 \%$ (15 of 72) of DTC tumor tissue. Therefore, this mutation was investigated in blood samples of DTC cases and controls as a potential genetic polymorphism.

Characteristics of patients with TC for blood analysis. A total of 180 patients with DTC, along with 220 healthy controls, were selected for the study of HRAS T81C polymorphism. Out of 180 DTC cases, $72.8 \%$ (131 of 180) were $<55$ years of age and $27.2 \%$ (49 of 180 ) were $\geq 55$ years of age; $37.7 \%$ (68 of 180) were male and $62.3 \%$ (112 of 180) were female.
The proportion of non-smokers was $68.8 \%$ (124 of 180) and that of smokers was $31.2 \%$ (56 of 180). The cases and controls were matched with respect to sex, age, dwelling and smoking status $(\mathrm{P}=0.18 ; 0.91 ; 0.46$ and 0.83$)$. Socio-demographic and clinicopathological characteristics of DTC cases and controls are listed in Table IV.

Analysis of HRAS T81C SNP. PCR amplified product of HRAS exon 1 and fragment digestion of PCR product by DraIII restriction enzyme is shown in Fig. 3. Frequency distribution of HRAS T81C genotypes TT, TC and CC among cases were $37.7,46.1$ and $16.1 \%$, respectively, in patients, compared with $54.5,34.1$ and $11.4 \%$, respectively, in controls. Furthermore, the allele frequency of $\mathrm{T}$ and $\mathrm{C}$ among cases was 60.8 and $39.2 \%$, respectively, and 71.5 and $28.5 \%$, respectively, in controls. The difference in genotypic and allele frequency between cases and controls was statistically significant $(\mathrm{P} \leq 0.05$; Table V). As the frequency of homozygous mutant (CC) genotype was low, 
Table II. Frequency distribution of selected socio-demographic and clinicopathological characteristics of DTC cases for mutational analysis.

\section{Characteristic}

Sex

Male

Female

$22.0(30.6)$

$50.0(69.4)$

Age, years

$<55$

$\geq 55$

$54.0(75.0)$

$18.0(25.0)$

Smoking status

Non-smoker

Smoker

$65.0(90.0)$

$7.0(10.0)$

TSH levels

Normal

$42.0(58.4)$

Elevated

30.0 (41.6)

\section{BTD}

Absent

$58.0(80.5)$

Present

$14.0(19.5)$

Histological type

CPTC

FPTC

$27.0(37.5)$

Grade

WD

PD

$68.0(94.0)$

$4.0(6.0)$

Tumor focality

Unifocal

40.0 (55.6)

Multifocal

$32.0(44.4)$

Stage, $<55$ years

I

$21.0(39.0)$

II

$33.0(61.0)$

Stage, $\geq 55$ years

I+II

$7.0(39.0)$

$\geq$ III

$\mathrm{V} / \mathrm{C}$ invasion

Absent

$31.0(43.1)$

Present

41.0 (56.9)

LN metastasis

Absent

$33.0(45.8)$

Present

CPTC, Classical variant of papillary thyroid cancer; FPTC, follicular variant of papillary thyroid cancer; LN, lymph node; TSH, thyroid stimulating hormone; BTD, benign thyroid disease; WD, well-differentiated; PD, poorly differentiated; V/C, vascular/capsular.

the combined variant $(\mathrm{TC}+\mathrm{CC})$ genotype was compared with homozygous wild genotype (TT) between cases and controls to investigate the increased cancer risk associated with variant genotypes. Overall frequency of TC + CC was significantly greater in cases compared with controls (62.2 vs. $45.4 \%)$ with OR of 2.0 (95\% CI, 1.3-2.9; $\mathrm{P}=0.0009$; Table V).
Genotype frequencies of $\mathrm{TT}$ and $\mathrm{TC}+\mathrm{CC}$ were compared between DTC cases and controls with respect to different socio-demographic and clinicopathological parameters (Table VI). The results indicated significantly higher frequency of variant genotype $(\mathrm{TC}+\mathrm{CC})$ in male patients with DTC compared with males in the control group (61.7 vs. 40.8\%; $\mathrm{P}=0.01$ ). Age was a strong risk factor for DTC as the difference in the frequency of TC + CC genotype between cases and controls $\geq 55$ years of age was significant (59.27 vs. $19.3 \%$; $\mathrm{P}=0.00002$; $\mathrm{OR}=6.0$ ). Similarly, patients with DTC living in rural areas had significantly higher frequency of variant genotype (TC + CC) compared with controls (62.57 vs. 42.1\%; $\mathrm{P}=0.001$ ). Furthermore, combined TC and CC genotype was significantly greater in non-smoker DTC patientcompared with non-smoker control group (61.37 vs. 44.9\%; $\mathrm{P}=0.007$ ). TC and CC were frequently observed in patients with DTC without history of BTD compared with patients with BTD (76.07 vs. 52.3\%; $\mathrm{P}=0.002$ ). A high frequency of variant genotype $(\mathrm{TC}+\mathrm{CC})$ was found in patients with DTC with multifocal disease (70.27 vs. $55.2 \% ; \mathrm{P}=0.04)$ and $\mathrm{LN}$ metastasis (84.37 vs. $48.2 \%$; $\mathrm{P}=0.00001$ ) compared with patients with unifocal disease and without LN metastasis. Association of rare variants $(\mathrm{TC}+\mathrm{CC}$ ) with other socio-demographic and clinicopathological parameters of DTC cases and controls is shown in Table VI.

Genetic association study of HRAS T81C polymorphism. Various inheritance models were applied to asses the inhertence pattern of polymorphism. A significantly higher frequency of of variant genotype $(\mathrm{TC}+\mathrm{CC})$ was observed in DTC cases as compared with controls (62.27 vs. $45.4 ; \mathrm{P}=0.0009)$ indicating the ominant mode of inheritance. Table VII depicts the results of the association study for HRAS T81C SNP.

Patient follow-up. The patients were followed until the end of radioiodine therapy (data not shown). In patients with DTC lacking $B R A F^{\mathrm{V} 600 \mathrm{E}}$ mutation, low doses of I-131 $(2.5-3 \mathrm{mCi})$ were given and patients responded well with high uptake. In addition, patients with DTC with $B R A F^{\mathrm{V} 600 \mathrm{E}}$ mutation exhibited decreased uptake of I-131 at low doses; therefore high doses of I-131 were given (75-80 $\mathrm{mCi}$ ) for proper uptake and subsequent response to radio-iodine therapy.

\section{Discussion}

The MAP kinase pathway serves as a signal transducer between the extracellular environment and the nucleus (26). Extracellular signals, such as hormones and growth factors, interact with RET to activate small G-proteins of the RAS family, which activate and recruit RAF protein to the cell membrane where it is activated (27). Active BRAF signals via MEK to activate ERK, which activates downstream transcription factors to induce cell differentiation, proliferation, growth and apoptosis (28).

Triggering kinase activity makes BRAF a potent activator of MEK. $B R A F^{\mathrm{V} 600 \mathrm{E}}$ mutation increases the kinase activity of BRAF by nearly 700 -fold, thereby stimulating constitutive activation of MEK/ERK signaling in tumor cells in the absence of extracellular stimuli, allowing the cell to become self-sufficient in growth signals within this pathway (28). Here, $B R A F^{\mathrm{V} 600 \mathrm{E}}$ 
Table III. Association of $B R A F^{V 600 E}$ mutation status with demographic and clinicopathological features of patients with DTC.

\begin{tabular}{|c|c|c|c|c|}
\hline \multirow[b]{2}{*}{ Characteristic } & \multirow[b]{2}{*}{$\begin{array}{c}\text { Cases, } \\
\mathrm{n}=72(\%)\end{array}$} & \multicolumn{2}{|c|}{$B R A F^{V 600 E}$ mutation } & \multirow[b]{2}{*}{ P-value } \\
\hline & & $\begin{array}{c}\text { Positive, } \\
\mathrm{n}=20(27.7 \%)\end{array}$ & $\begin{array}{c}\text { Negative, } \\
\mathrm{n}=52(72.3 \%)\end{array}$ & \\
\hline \multicolumn{5}{|l|}{ Sex } \\
\hline Male & $22.0(30.6)$ & $9.0(41.0)$ & $13.0(59.0)$ & \multirow[t]{2}{*}{0.1000} \\
\hline Female & $50.0(69.4)$ & $11.0(22.0)$ & $39.0(78.0)$ & \\
\hline \multicolumn{5}{|l|}{ Age, years } \\
\hline$<55$ & $54.0(75.0)$ & $14.0(26.0)$ & $40.0(74.0)$ & \multirow[t]{2}{*}{0.7000} \\
\hline$\geq 55$ & $18.0(25.0)$ & $6.0(33.3)$ & $12.0(66.7)$ & \\
\hline \multicolumn{5}{|l|}{ Smoking status } \\
\hline Non-smoker & $65.0(90.0)$ & $18.0(24.6)$ & $47.0(75.4)$ & \multirow[t]{2}{*}{0.6000} \\
\hline Smoker & $7.0(10.0)$ & $2.0(85.7)$ & $5.0(14.3)$ & \\
\hline \multicolumn{5}{|l|}{ TSH levels } \\
\hline Normal & $42.0(58.4)$ & $10.0(23.8)$ & $32.0(76.2)$ & \multirow[t]{2}{*}{0.4000} \\
\hline Elevated & $30.0(41.6)$ & $10.0(33.3)$ & $20.0(66.7)$ & \\
\hline \multicolumn{5}{|l|}{ BTD } \\
\hline Absent & $58.0(80.5)$ & $15.0(25.8)$ & $43.0(74.2)$ & \multirow[t]{2}{*}{0.3000} \\
\hline Present & $14.0(19.5)$ & $5.0(35.7)$ & $9.0(64.3)$ & \\
\hline \multicolumn{5}{|c|}{ Histological type } \\
\hline CPTC & $45.0(62.5)$ & $20.0(44.4)$ & $25.0(55.6)$ & \multirow[t]{2}{*}{$0.0001^{\mathrm{a}}$} \\
\hline FPTC & $27.0(37.5)$ & $0.0(0.0)$ & $27.0(100.0)$ & \\
\hline \multicolumn{5}{|l|}{ Grade } \\
\hline WD & $68.0(94.0)$ & $18.0(26.4)$ & $50.0(73.6)$ & \multirow[t]{2}{*}{0.5000} \\
\hline $\mathrm{PD}$ & $4.0(6.0)$ & $2.0(50.0)$ & $2.0(50.0)$ & \\
\hline \multicolumn{5}{|l|}{ Tumor focality } \\
\hline Unifocal & $40.0(55.6)$ & $7.0(17.5)$ & $33.0(82.5)$ & \multirow[t]{2}{*}{$0.0300^{\mathrm{a}}$} \\
\hline Multifocal & $32.0(44.4)$ & $13.0(41.0)$ & $19.0(59.0)$ & \\
\hline \multicolumn{5}{|l|}{ Stage, $<55$ years } \\
\hline I & $21.0(39.0)$ & $8.0(38.0)$ & $13.0(62.0)$ & \multirow[t]{2}{*}{0.1000} \\
\hline II & $33.0(61.0)$ & $6.0(18.0)$ & $27.0(81.0)$ & \\
\hline \multicolumn{5}{|l|}{ Stage, $\geq 55$ years } \\
\hline $\mathrm{I}+\mathrm{II}$ & $7.0(39.0)$ & $2.0(28.5)$ & $5.0(71.5)$ & \multirow[t]{2}{*}{0.5000} \\
\hline$\geq \mathrm{III}$ & $11.0(61.0)$ & $4.0(36.4)$ & $7.0(63.6)$ & \\
\hline \multicolumn{5}{|l|}{$\mathrm{V} / \mathrm{C}$ Invasion } \\
\hline Absent & $31.0(43.1)$ & $6.0(19.0)$ & $25.0(81.0)$ & \multirow[t]{2}{*}{0.1000} \\
\hline Present & $41.0(56.9)$ & $14.0(34.1)$ & $27.0(65.8)$ & \\
\hline LN metastasis & & & & $0.0050^{\mathrm{a}}$ \\
\hline Absent & $33.0(45.8)$ & $4.0(15.2)$ & $29.0(84.8)$ & \\
\hline Present & $39.0(54.2)$ & $16.0(41.0)$ & $23.0(59.0)$ & \\
\hline
\end{tabular}

${ }^{\mathrm{a}} \mathrm{P}<0.05$. DTC, differentiated thyroid cancer; CPTC, classical variant of papillary thyroid cancer; FPTC, follicular variant of papillary thyroid cancer; LN, lymph node; TSH, thyroid stimulating hormone; BTD, benign thyroid disease; WD, well-differentiated; PD, poorly differentiated; $\mathrm{V} / \mathrm{C}$, vascular/capsular.

mutation was found in $28 \%$ of patients with DTC. $B R A F^{\mathrm{V} 600 \mathrm{E}}$ mutation has been detected in $40-70 \%$ of malignant melanoma, $45-55 \%$ of DTC and $10 \%$ of colorectal cancer (29). In addition the $B R A F^{\mathrm{V} 600 \mathrm{E}}$ mutation has also been identified in ovarian, breast and lung cancer $(9,30,31)$. Clinically, FPTC metastasizes to cervical lymph nodes less frequently than CPTC but has a similar survival rate $(29,32)$. In the present study, the $B R A F^{\mathrm{V} 600 \mathrm{E}}$ mutation was present in $44.4 \%$ of CPTC cases but absent in FPTC cases. The prevalence of $B R A F^{\mathrm{V} 600 \mathrm{E}}$ mutation in CPTC is $50-60 \%(9,10,33)$. Studies have shown that FPTC molecular profile may be different from that of CPTC $(34,35)$. Additionally, it has been reported that FPTC has lower BRAF but higher $R A S$ 
Table IV. Frequency distribution of socio-demographic and clinicopathological characteristics of DTC cases and controls for HRAS T81C genotyping

\begin{tabular}{|c|c|c|c|c|}
\hline Characteristic & Cases, $\mathrm{n}=180(\%)$ & Controls, $\mathrm{n}=220(\%)$ & $\chi^{2}$ & P-value \\
\hline Sex & & & 1.87 & 0.18 \\
\hline Male & $68.0(37.7)$ & $98.0(44.5)$ & & \\
\hline Female & $112.0(62.3)$ & $122.0(55.5)$ & & \\
\hline \multicolumn{5}{|l|}{ Age, years } \\
\hline$<55$ & $131.0(72.8)$ & $158.0(71.8)$ & 0.05 & 0.91 \\
\hline$\geq 55$ & $49.0(27.2)$ & $62.0(28.2)$ & & \\
\hline \multicolumn{5}{|l|}{ Dwelling } \\
\hline Rural & $120.0(66.6)$ & $138.0(62.7)$ & 0.67 & 0.46 \\
\hline Urban & $60.0(33.4)$ & $82.0(37.2)$ & & \\
\hline \multicolumn{5}{|l|}{ Smoking status } \\
\hline Non-smoker & $124.0(68.8)$ & $149.0(67.7)$ & 0.06 & 0.83 \\
\hline Smoker & $56.0(31.2)$ & $71.0(32.3)$ & & \\
\hline \multicolumn{5}{|l|}{ BTD } \\
\hline Absent & $75.0(41.6)$ & & & \\
\hline Present & $105.0(58.3)$ & & & \\
\hline \multicolumn{5}{|c|}{ Histological type } \\
\hline PTC & $151.0(83.9)$ & & & \\
\hline FTC & $29.0(16.1)$ & & & \\
\hline \multicolumn{5}{|l|}{ TSH levels } \\
\hline Normal & $52.0(28.9)$ & & & \\
\hline Elevated & $128.0(71.1)$ & & & \\
\hline \multicolumn{5}{|l|}{ Grade } \\
\hline WD & $176.0(97.8)$ & & & \\
\hline PD & $4.0(2.2)$ & & & \\
\hline \multicolumn{5}{|l|}{ Tumor focality } \\
\hline Unifocal & $96.0(53.3)$ & & & \\
\hline Multifocal & $84.0(46.7)$ & & & \\
\hline \multicolumn{5}{|c|}{ Stage, $<55$ years } \\
\hline I & $65.0(36.1)$ & & & \\
\hline II & $66.0(36.7)$ & & & \\
\hline \multicolumn{5}{|c|}{ Stage, $\geq 55$ years } \\
\hline $\mathrm{I}+\mathrm{II}$ & $26.0(14.4)$ & & & \\
\hline$\geq \mathrm{III}$ & $23.0(12.8)$ & & & \\
\hline \multicolumn{5}{|l|}{$\mathrm{V} / \mathrm{C}$ invasion } \\
\hline Absent & $93.0(51.7)$ & & & \\
\hline Present & $87.0(48.3)$ & & & \\
\hline \multicolumn{5}{|l|}{ LN metastasis } \\
\hline Absent & $110.0(61.1)$ & & & \\
\hline Present & $70.0(38.9)$ & & & \\
\hline
\end{tabular}

DTC, differentiated thyroid cancer; BTD, benign thyroid disease; PTC, papillary thyroid cancer; FTC, follicular thyroid cancer; TSH, thyroid stimulating hormone; WD, well-differentiated; PD, poorly differentiated; V/C, vascular/capsular; LN, lymph node.

mutation rate compared with CPTC (36). The present study demonstrated an association between $B R A F^{\mathrm{V} 600 \mathrm{E}}$ mutation and multifocality and LN metastasis in DTC. Accumulating data have shown that $B R A F^{\mathrm{V} 600 \mathrm{E}}$ mutation is associated with unfavourable clinicopathological characteristics, such as extrathyroidal extension, LN metastasis, recurrence and advanced disease stage in DTC $(37,38) . B R A F^{\mathrm{V} 600 \mathrm{E}}$ is associated with silencing of multiple thyroid-specific iodine-metabolizing genes such as sodium/iodide symporter and apical iodide transporter, responsible for transportation of inorganic iodine into thyroid cells $(39,40)$. Consequently, tumors harbouring the mutation are, to an extent, resistant to radio iodine abalation 
Table V. Distribution of HRAS T81C genotypes and its allele frequency in DTC cases and controls for HRAS T81C genotyping.

\begin{tabular}{|c|c|c|c|c|}
\hline Type & DTC cases, $\mathrm{n}=180(\%)$ & Controls, $\mathrm{n}=220(\%)$ & OR $(95 \% \mathrm{CI})$ & P-value \\
\hline \multicolumn{5}{|l|}{ Genotype } \\
\hline TT & $68.0(37.7)$ & $120.0(54.5)$ & $1.00(\mathrm{Ref})$ & \\
\hline $\mathrm{TC}$ & $83.0(46.1)$ & $75.0(34.1)$ & $1.90(1.30-3.00)$ & $0.0020^{\mathrm{a}}$ \\
\hline $\mathrm{CC}$ & $29.0(16.1)$ & $25.0(11.4)$ & $2.05(1.10-3.80)$ & $0.0300^{\mathrm{a}}$ \\
\hline $\mathrm{TC}+\mathrm{CC}$ & $112.0(62.2)$ & $100.0(45.4)$ & $2.00(1.30-2.90)$ & $0.0009^{\mathrm{a}}$ \\
\hline \multicolumn{5}{|l|}{ Allele } \\
\hline $\mathrm{T}$ & $219.0(60.8)$ & $315.0(71.5)$ & 1.00 (Ref) & \\
\hline $\mathrm{C}$ & $141.0(39.2)$ & $125.0(28.5)$ & $1.60(1.20-2.20)$ & $0.0010^{\mathrm{a}}$ \\
\hline
\end{tabular}

${ }^{\mathrm{a}} \mathrm{P}<0.05$. DTC, differentiated thyroid cancer; TC, genotype formed by combination of thymine and cytosine residues; TT, genotype with combination of two thymine residues; $\mathrm{CC}$ genotype formed by combination of two cytosine residues.

used for the treatment of TC, which may explain the more aggressive phenotype exhibited by DTC harboring $B R A F^{\mathrm{V} 600 \mathrm{E}}$ mutation (41).

$R A S$ is the most commonly mutated gene family in TC that contributes to cancer initiation and progression via inhibition of GTP hydrolysis by diminishing GTPase activity (42). Gain of function mutations in the hotspot regions of the RAS gene family affect codons 12 and 13 in exon 1 and codon 61 in exon 2. No mutation in any of the $R A S$ genes was found in the present study, which supports previous studies indicating that mutations in $B R A F$ and $R A S$ generally occur in a mutually exclusive manner $(42,43)$. Mutual exclusiveness suggests that MAP kinase pathway is controlled at different levels to regulate TC pathogenesis. Certain studies observed an increase in $R A S$ mutation in dietary iodine-deficient countries, such as eastern Hungary and Japan $(44,16)$ whereas, Vuong et al $(45)$ reported no difference in frequency of $R A S$ mutations between iodine-rich and -deficient countries.

To the best of our knowledge, the present study is the first multicentric study from Pakistan exploring the utility of HRAS T81C SNP analysis in TC risk, which may help in future treatment modalities. HRAS T81C SNP was found to be a strong risk factor for TC $(22,24)$. The HRAS T81C variant $(\mathrm{TC}+\mathrm{CC})$ and heterozygous genotype (TC) were found in 62.2 and $46.1 \%$ of patients with TC compared with 45.4 and $34.1 \%$ of controls, respectively; these rates are higher in comparison with other ethnic groups $(21,46)$. The reason for the higher frequency of variant genotype in DTC cases compared withcontrols may be attributed to geographical differences and relatively small sample size (21). In addition, HRAS T81C was significantly associated with the risk of DTC in the present study $(\mathrm{P}=0.0009)$. Earlier studies have also reported significant association of HRAS T81C SNP with risk of gastric, colon and bladder cancer $(47,48)$, although, the frequency of variant genotype reported by those studies was relatively less compared with the present study

Following stratification of HRAS T81C genotypes with clinicopathological risk factors in patients with DTC, TC and $\mathrm{CC}$ variants have been significantly associated with higher age, which is in line with previous studies that identified higher age as a key risk factor for tumorogenesis in relation to HRAS T81C gene polymorphism $(48,49)$. However, an earlier study demonstrated no significant association of age with risk of thyroid cancer in relation to HRAS T81C genotypes (22). Males and rural dwellers with DTC exhibited greater frequency of TC + CC compared with control males and rural dwellers, which differs from earlier studies $(22,47)$. The present results demonstrated that variant genotype $(\mathrm{TC}+\mathrm{CC}$ ) was inversely associated to smoking status. Ciggarete smoking may lower endogenous TSH levels in the body and hence lower the risk of TC (50). These results were different to earlier studies, in which no association of TSH level with smoking was found $(51,52)$. Patients with DTC with no history of BTD had greater frequency of TC + CC genotype. Khan et al (22) found no association between HRAS T81C genotype and history of BTD. As BTD is a risk factor and molecular crosstalk occurs during the initiation and progression of cancer, there may be other molecular changes responsible for the development of BTD, which may serve a role in the development of cancer phenotype. Although previous history of BTD was recorded, the present study included histologically confirmed patients with DTC rather than patients with any BTD. Investigation of MAP kinase pathway aberrations in Pakistani individuals with BTD will improve understanding of the etiopathogenesis of TC in this region. In the present study, HRAS T81C variant genotype was associated with multifocality and $\mathrm{LN}$ metastasis $(\mathrm{P} \leq 0.05)$. An earlier studies demonstrated no significant association of variant genotype with multifocality and LN metastasis (53). The present study did not observe any association between histological type, tumor grade, TSH levels, V/C invasion and tumor stage with HRAS T81C TC + CC genotype. However, Krishna et al (54) showed high expression of HRAS protein in WDTC and higher stage. A previous study has reportedno association between $H R A S T 81 C$ variants and histological types of TC (55).

Although the mechanism underlying the role of HRAS T81C SNP in cancer initiation is not completely known, this SNP may not be involved in delaying GTP-bound activated state (56) and alteration of the $R A S$ protein structure (24), but rather affect cancer susceptibility via linkage with other polymorphic sites in functional intron regions of HRAS (57,58). HRAS T81C exon 1 may be linked to rs112587690 SNP in intron 1 and L-myc rs3134613 SNP in the development of cutaneous melanoma and colorectal cancer, respectively $(57,58)$. The polymorphism may also be linked to a candidate region with variable tandem repeat present downstream of exon 4 , exhibiting possible 


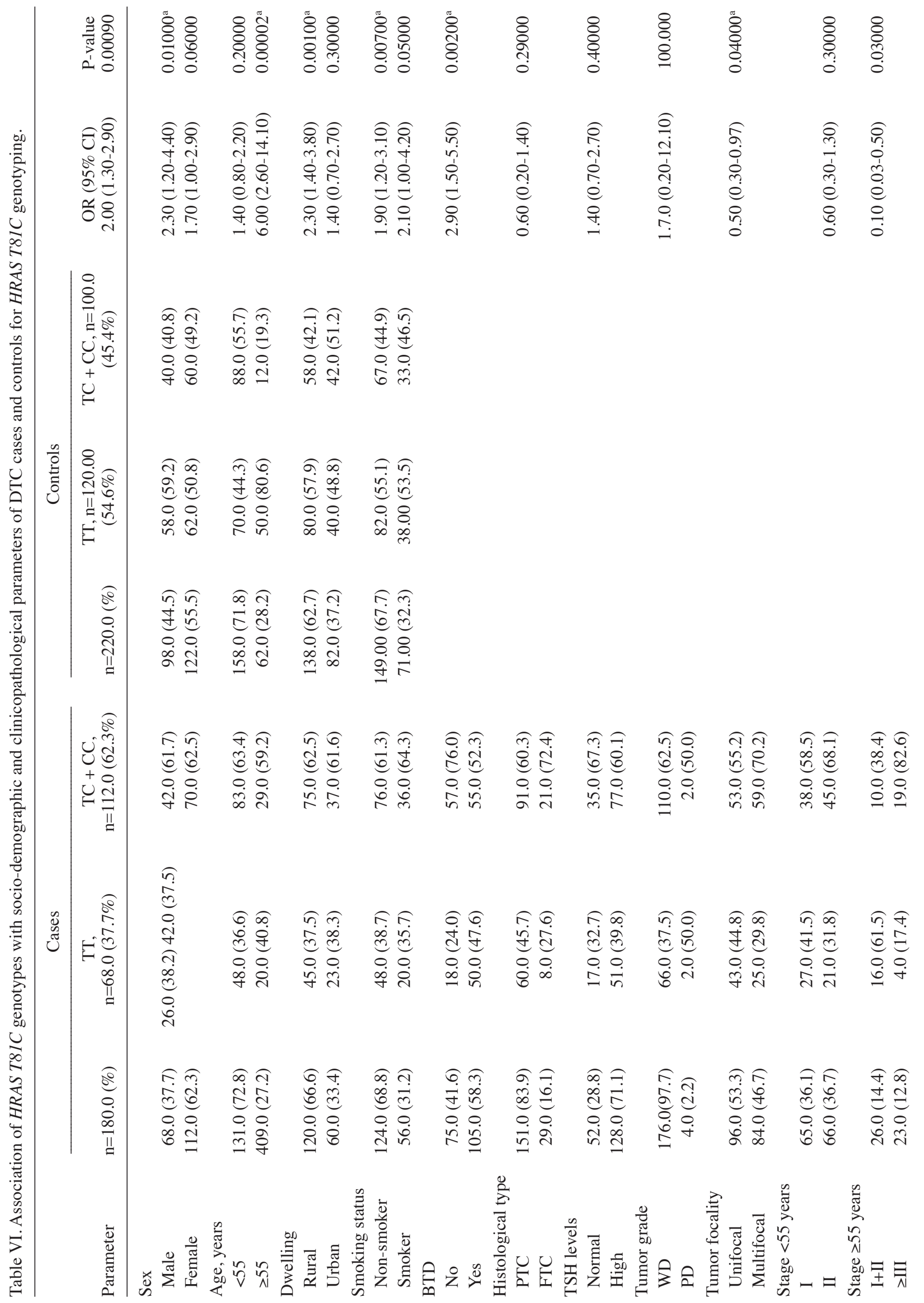




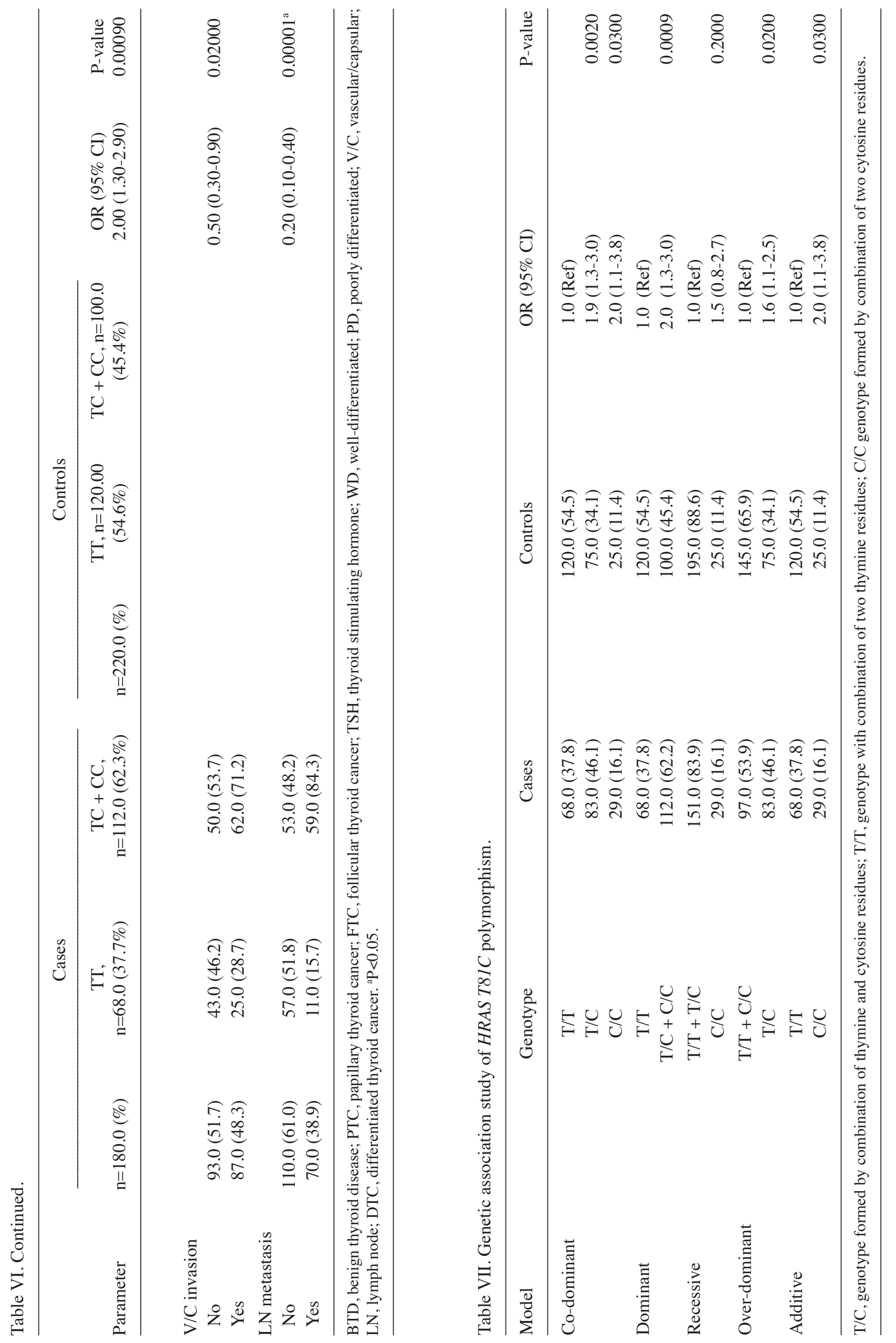


transcriptional enhancer activity (59). Furthermore, reports have shown the association of HRAS T81C SNP with hexanucleotide region present 80 bp upstream of $5^{\prime}$ exon $1(55,60,61)$. Additionally, the HRAS T81C SNP is also associated with polymorphic intron D2 (dopamine) region of HRAS that may serve as a regulator of Intron D Exon inclusion (24). HRAS T81C polymorphism follows a dominant mode of inheritance, which assumes that carriers of wild genotypes are associated with lower cancer risk compared with heterozygous and rare genotypes (62).

As the sample size of the present study was modest, further studies with larger sample size and follow-up of patients are required to authenticate the association to better distinguish racial and ethnic differences affecting the pathogenesis and severity of DTC.

In summary, $B R A F^{\mathrm{V} 600 \mathrm{E}}$ mutation may be implicated in the pathogenesis of DTC in a mutual exclusive manner with $R A S$ mutations in Kashmiri population. $B R A F^{\mathrm{V} 600 \mathrm{E}}$ mutation was confined to CPTC variant and was significantly associated with multifocality and LN metastasis, suggesting that $B R A F^{\mathrm{V} 600 \mathrm{E}}$ mutation may be useful for evaluation of prognosis of patients with DTC. These results indicated that $B R A F$ may be a promising target for pharmacological intervention in DTC. HRAS T81C varant genotype was increased in DTC with dominant pattern of inheritence. HRAS T81C variant genotype increased risk of DTC with no history of smoking, males, higher age, multifocality and LN metatasis. Further analysis of other genetic markers and long-term clinical follow-up may improve understanding of DTC.

\section{Acknowledgements}

Not applicable.

\section{Funding}

The present study was funded by International Islamic University, Islamabad (grant no. NRPU 8038).

\section{Availability of data and materials}

The datasets used and/or analyzed during the current study are available from the corresponding author on reasonable request.

\section{Authors' contributions}

FAR, GHB and MSK conceptualized the study, collected data and wrote the manuscript. GHB and MSK analyzed the data and reviewed and edited the manuscript. FAR and ST performed the experiments. ST supervized the study and provided resources. FAR and ST visualized the data. MSK and GHB confirm the authenticity of all the raw data. All authors read and approved the final version of the manuscript.

\section{Ethics approval and consent to participate}

The present study was approved by the Ethical Review Board of PIMS (approval no.F.1-1/2015/ERB/SZABMU). All samples were collected with written informed consent from patients and proper ethical procedures were followed.

\section{Patient consent for publication}

Not applicable.

\section{Competing interests}

The authors declare that they have no competing interests.

\section{References}

1. Sung H, Ferlay J, Siegel RL, Laversanne M, Soerjomataram I, Jemal A and Bray F: Global Cancer Statistics 2020: GLOBOCAN Estimates of Incidence and Mortality Worldwide for 36 Cancers in 185 Countries. CA Cancer J Clin 71: 209-249, 2021.

2. Morris LG, Tuttle RM and Davies L: Changing trends in the incidence of thyroid cancer in the United States. JAMA Otolaryngol Head Neck Surg 142: 709-711, 2016.

3. Nikiforov YE, Seethala RR, Tallini G, Baloch ZW, Basolo F, Thompson LD, Barletta JA, Wenig BM, Al Ghuzlan A, Kakudo K, et al: Nomenclature revision for encapsulated follicular variant of papillary thyroid carcinoma: A paradigm shift to reduce overtreatment of indolent tumors. JAMA Oncol 2: 1023-1029, 2016.

4. Laha D, Nilubol $\mathrm{N}$ and Boufraqech M: New Therapies for Advanced Thyroid Cancer. Front Endocrinol (Lausanne) 11: 82, 2020.

5. Nikiforov YE: Thyroid carcinoma: Molecular pathways and therapeutic targets. Mod Pathol 21 (Suppl 2): S37-S43, 2008.

6. Dvorak K, Aggeler B, Palting J, McKelvie P, Ruszkiewicz A and Waring P: Immunohistochemistry with the anti-BRAF V600E (VE1) antibody: Impact of pre-analytical conditions and concordance with DNA sequencing in colorectal and papillary thyroid carcinoma. Pathology 46: 509-517, 2014.

7. Wan PT, Garnett MJ, Roe SM, Lee S, Niculescu-Duvaz D, Good VM, Jones CM, Marshall CJ, Springer CJ, Barford D, et al; Cancer Genome Project: Mechanism of activation of the RAF-ERK signaling pathway by oncogenic mutations of B-RAF. Cell 116: 855-867, 2004.

8. Oh HS, Kwon H, Park S, Kim M, Jeon MJ, Kim TY, Shong YK, Kim WB, Choi J, Kim WG, et al: Comparison of Immunohistochemistry and Direct Sanger Sequencing for Detection of the BRAF(V600E) Mutation in Thyroid Neoplasm. Endocrinol Metab (Seoul) 33: 62-69, 2018.

9. Xing M: BRAF mutation in thyroid cancer. Endocr Relat Cancer 12: 245-262, 2005.

10. Kim TY, Kim WB, Rhee YS, Song JY, Kim JM, Gong G, Lee S, Kim SY, Kim SC, Hong SJ, et al: The BRAF mutation is useful for prediction of clinical recurrence in low-risk patients with conventional papillary thyroid carcinoma. Clin Endocrinol (Oxf) 65: 364-368, 2006.

11. Kondo T, Ezzat S, Asa SL. Pathogenetic mechanisms in thyroid follicular-cell neoplasia. Nat Rev Cancer 6: 292-306, 2006.

12. Mo SP, Coulson JM and Prior IA: RAS variant signalling. Biochem Soc Trans 46: 1325-1332, 2018.

13. Takai Y, Sasaki T and Matozaki T: Small GTP-binding proteins. Physiol Rev 81: 153-208, 2001.

14. Castellano E and Santos E: Functional specificity of ras isoforms: So similar but so different. Genes Cancer 2: 216-231, 2011.

15. Chakladar J, Li WT, Bouvet M, Chang EY, Wang-Rodriguez J and Ongkeko WM: Papillary thyroid carcinoma variants are characterized by co-dysregulation of immune and cancer associated genes. Cancers (Basel) 11: 1179, 2019.

16. Motoi N, Sakamoto A, Yamochi T, Horiuchi H, Motoi T and Machinami R: Role of ras mutation in the progression of thyroid carcinoma of follicular epithelial origin. Pathol Res Pract 196: $1-7,2000$.

17. Garcia-Rostan G,Zhao H, Camp RL, Pollan M, Herrero A, Pardo J, Wu R, Carcangiu ML, Costa J and Tallini G: ras mutations are associated with aggressive tumor phenotypes and poor prognosis in thyroid cancer. J Clin Oncol 21: 3226-3235, 2003.

18. Ezzat S, Zheng L, Kolenda J, Safarian A, Freeman JL and Asa SL: Prevalence of activating ras mutations in morphologically characterized thyroid nodules. Thyroid 6: 409-416, 1996.

19. Zhu Z, Gandhi M, Nikiforova MN, Fischer AH and Nikiforov YE: Molecular profile and clinical-pathologic features of the follicular variant of papillary thyroid carcinoma. An unusually high prevalence of ras mutations. Am J Clin Pathol 120: 71-77, 2003. 
20. Hara H, Fulton N, Yashiro T, Ito K, DeGroot LJ and Kaplan EL: N-ras mutation: An independent prognostic factor for aggressiveness of papillary thyroid carcinoma. Surgery 116: 1010-1016, 1994.

21. Howell GM, Hodak SP and Yip L: RAS mutations in thyroid cancer. Oncologist 18: 926-932, 2013.

22. Khan MS, Pandith AA, U1 Hussain M, Iqbal M, Khan NP, Wani KA, Masoodi SR and Mudassar S: Lack of mutational events of RAS genes in sporadic thyroid cancer but high risk associated with HRAS T81C single nucleotide polymorphism (case-control study). Tumour Biol 34: 521-529, 2013.

23. Wang Y, Gao W, Guo Y and Peng C: The role of HRAS rs 12628 polymorphism in cancer risks: Evidence from a meta-analysis of 19 case-control studies. Int J Clin Exp Med 10: 2386-2396, 2017.

24. Castro P, Soares P, Gusmão L, Seruca R and Sobrinho-Simões M: H-RAS 81 polymorphism is significantly associated with aneuploidy in follicular tumors of the thyroid. Oncogene 25: 4620-4627, 2006.

25. Khan MS, Pandith AA, Azad N, Hussain MU, Masoodi SR, Wani KA, Andrabi KI and Mudassar S: Impact of molecular alterations of BRAF in the pathogenesis of thyroid cancer. Mutagenesis 29: 131-137, 2014.

26. Morrison DK: MAP kinase pathways. Cold Spring Harb Perspect Biol 4: a011254, 2012

27. Garnett MJ and Marais R: Guilty as charged: B-RAF is a human oncogene. Cancer Cell 6: 313-319, 2004

28. Cantwell-Dorris ER, O'Leary JJ and Sheils OM: BRAFV600E: Implications for carcinogenesis and molecular therapy. Mol Cancer Ther 10: 385-394, 2011.

29. Pakneshan S, Salajegheh A, Smith RA and Lam AK: Clinicopathological relevance of BRAF mutations in human cancer. Pathology 45: 346-356, 2013.

30. Davies H, Bignell GR, Cox C, Stephens P, Edkins S, Clegg S Teague J, Woffendin H, Garnett MJ, Bottomley W, et al: Mutations of the BRAF gene in human cancer. Nature 417: 949-954, 2002

31. Sahin IH and Klostergaard J: BRAF mutations as actionable targets: A paradigm shift in the management of colorectal cancer and novel avenues. JCO Oncol Pract: Jun 2, 2021 (Epub ahead of print). doi: 10.1200/OP.21.00160

32. Kebebew E and Clark OH: Differentiated thyroid cancer: 'complete' rational approach. World J Surg 24: 942-951, 2000.

33. Kim J, Giuliano AE, Turner RR, Gaffney RE, Umetani N, Kitago M, Elashoff D and Hoon DS: Lymphatic mapping establishes the role of BRAF gene mutation in papillary thyroid carcinoma. Ann Surg 244: 799-804, 2006.

34. Lupi C, Giannini R, Ugolini C, Proietti A, Berti P, Minuto M, Materazzi G, Elisei R, Santoro M, Miccoli P, et al: Association of BRAF V600E mutation with poor clinicopathological outcomes in 500 consecutive cases of papillary thyroid carcinoma. J Clin Endocrinol Metab 92: 4085-4090, 2007.

35. Abdullah MI, Junit SM, Ng KL, Jayapalan JJ, Karikalan B and Hashim OH: Papillary Thyroid Cancer: Genetic Alterations and Molecular Biomarker Investigations. Int J Med Sci 16: 450-460, 2019.

36. Adeniran AJ, Zhu Z, Gandhi M, Steward DL, Fidler JP, Giordano TJ, Biddinger PW and Nikiforov YE: Correlation between genetic alterations and microscopic features, clinical manifestations, and prognostic characteristics of thyroid papillary carcinomas. Am J Surg Pathol 30: 216-222, 2006

37. Xing M, Westra WH, Tufano RP, Cohen Y, Rosenbaum E, Rhoden KJ, Carson KA, Vasko V, Larin A, Tallini G, et al: BRAF mutation predicts a poorer clinical prognosis for papillary thyroid cancer. J Clin Endocrinol Metab 90: 6373-6379, 2005.

38. Kebebew E, Weng J, Bauer J, Ranvier G, Clark OH, Duh QY, Shibru D, Bastian B and Griffin A: The prevalence and prognostic value of BRAF mutation in thyroid cancer. Ann Surg 246: 466-471, 2007

39. Liu D, Hu S, Hou P, Jiang D, Condouris S and Xing M: Suppression of BRAF/MEK/MAP kinase pathway restores expression of iodide-metabolizing genes in thyroid cells expressing the V600E BRAF mutant. Clin Cancer Res 13: 1341-1349, 2007.

40. Makboul R, Mostafa NM, El-Deek HEM, Aboulhagag NA, Shehata MR and Abdelhafez YG: Do BRAFV600E mutation and sodium-iodide symporter expression affect the response to radioactive iodine therapy in patients with papillary thyroid carcinoma? Nucl Med Commun 41: 416-425, 2020.

41. Durante C, Puxeddu E, Ferretti E, Morisi R, Moretti S, Bruno R, Barbi F, Avenia N, Scipioni A, Verrienti A, et al: BRAF mutations in papillary thyroid carcinomas inhibit genes involved in iodine metabolism. J Clin Endocrinol Metab 92: 2840-2843, 2007.
42. Li ZN, Zhao L, Yu LF and Wei MJ: BRAF and KRAS mutations in metastatic colorectal cancer: Future perspectives for personalized therapy. Gastroenterol Rep (Oxf) 8: 192-205, 2020.

43. Oikonomou E, Koustas E, Goulielmaki M and Pintzas A: BRAF vs. RAS oncogenes: Are mutations of the same pathway equal? Differential signalling and therapeutic implications. Oncotarget 5: 11752-11777, 2014.

44. Shi YF, Zou MJ, Schmidt H, Juhasz F, Stensky V, Robb D and Farid NR: High rates of ras codon 61 mutation in thyroid tumors in an iodide-deficient area. Cancer Res 51: 2690-2693, 1991.

45. Vuong HG, Kondo T, Oishi N, Nakazawa T, Mochizuki K, Inoue T, Tahara I, Kasai K, Hirokawa M, Tran TM, et al: Genetic alterations of differentiated thyroid carcinoma in iodine-rich and iodine-deficient countries. Cancer Med 5: 1883-1889, 2016.

46. Jung CK, Kim Y, Jeon S, Jo K, Lee S and Bae JS: Clinical utility of EZH1 mutations in the diagnosis of follicular-patterned thyroid tumors. Hum Pathol 81: 9-17, 2018.

47. Zhang Y, Jin M, Liu B, Ma X, Yao K, Li Q and Chen K: Association between H-RAS T81C genetic polymorphism and gastrointestinal cancer risk: A population based case-control study in China. BMC Cancer 8: 256, 2008.

48. Pandith AA, Shah ZA, Khan NP, Baba KM, Wani MS and Siddiqi MA: HRAS T81C polymorphism modulates risk of urinary bladder cancer and predicts advanced tumors in ethnic Kashmiri population. Urol Oncol 31: 487-492, 2013.

49. Rostami M, Kalaei Z, Pourhoseingholi MA and Kadivar M: Study on association between H-ras gene polymorphism and gastric adenocarcinoma risk. Gastroenterol Hepatol Bed Bench 6: 146-151, 2013

50. Cho A, Chang Y, Ahn J, Shin H and Ryu S: Cigarette smoking and thyroid cancer risk: A cohort study. Br J Cancer 119: 638-645, 2018

51. Jee SH, Samet JM, Ohrr H, Kim JH and Kim IS: Smoking and cancer risk in Korean men and women. Cancer Causes Control 15: 341-348, 2004.

52. Navarro Silvera SA, Miller AB and Rohan TE: Risk factors for thyroid cancer: A prospective cohort study. Int J Cancer 116: 433-438, 2005

53. Dou R, Zhang L, Lu T, Liu D, Mei F, Huang J and Qian L: Identification of a novel HRAS variant and its association with papillary thyroid carcinoma. Oncol Lett 15: 4511-4516, 2018.

54. Krishna A, Singh S, Singh V, Kumar V, Singh US and Sankhwar SN: Does Harvey-Ras gene expression lead to oral squamous cell carcinoma? A clinicopathological aspect. J Oral Maxillofac Pathol 22: 65-72, 2018.

55. Suarez HG, du Villard JA, Severino M, Caillou B, Schlumberger M, Tubiana M, Parmentier C and Monier R: Presence of mutations in all three ras genes in human thyroid tumors. Oncogene 5: 565-570, 1990

56. Lowy DR and Willumsen BM: Function and regulation of ras. Annu Rev Biochem 62: 851-891, 1993

57. Tomei S, Adams S, Uccellini L, Bedognetti D, De Giorgi V, Erdenebileg N, Ascierto ML, Reinboth J, Liu Q, Bevilacqua G, et al: Association between HRAS rs12628 and rs112587690 polymorphisms with the risk of melanoma in the North American population. Med Oncol 29: 3456-3461, 2012

58. Ni Q, Zhang YJ, Zhang SC, Jin MJ, Ma XY, Yao KY, Li QL and Chen K: Association between H-ras and L-myc gene polymorphisms and susceptibility to colorectal cancer. Zhonghua Zhong Liu Za Zhi 34: 15-20, 2012 (In Chinese).

59. Trepicchio WL and Krontiris TG: Members of the rel/NF-kappa B family of transcriptional regulatory proteins bind the HRAS1 minisatellite DNA sequence. Nucleic Acids Res 20: 2427-2434, 1992.

60. Kotsinas A, Gorgoulis VG, Zacharatos P, Mariatos G, Kokotas S, Liloglou T, Ikonomopoulos J, Zoumpourlis V, Kyroudi A, Field JK, et al: Additional characterization of a hexanucleotide polymorphic site in the first intron of human $\mathrm{H}$-ras gene: Comparative study of its alterations in non-small cell lung carcinomas and sporadic invasive breast carcinomas. Cancer Genet Cytogenet 126: $147-154,2001$

61. Sol-Church K, Stabley DL, Nicholson L, Gonzalez IL and Gripp KW: Paternal bias in parental origin of HRAS mutations in Costello syndrome. Hum Mutat 27: 736-741, 2006.

62. Wang Q: Cancer predisposition genes: Molecular mechanisms and clinical impact on personalized cancer care: Examples of Lynch and HBOC syndromes. Acta Pharmacol Sin 37: 143-149, 2016.

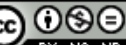

This work is licensed under a Creative Commons Attribution-NonCommercial-NoDerivatives 4.0 International (CC BY-NC-ND 4.0) License. 